\title{
Clinical characteristics, organ failure, inflammatory markers and prediction of mortality in patients with community acquired bloodstream infection
}

Vu Quoc Dat ${ }^{1,2,3^{*}}$ (D), Nguyen Thanh Long ${ }^{1}$, Vu Ngoc Hieu ${ }^{4}$, Nguyen Dinh Hong Phuc ${ }^{1}$, Nguyen Van Kinh ${ }^{3}$, Nguyen Vu Trung 3,4 . H. Rogier van Doorn ${ }^{2,5}$, Ana Bonell ${ }^{2}$ and Behzad Nadjm²,5

\begin{abstract}
Background: Community acquired bloodstream infection (CABSI) in low- and middle income countries is associated with a high mortality. This study describes the clinical manifestations, laboratory findings and correlation of SOFA and qSOFA with mortality in patients with CABSI in northern Vietnam.

Methods: This was a retrospective study of 393 patients with at least one positive blood culture with not more than one bacterium taken within $48 \mathrm{~h}$ of hospitalisation. Clinical characteristic and laboratory results from the first $24 \mathrm{~h}$ in hospital were collected. SOFA and qSOFA scores were calculated and their validity in this setting was evaluated.

Results: Among 393 patients with bacterial CABSI, approximately 80\% (307/393) of patients had dysfunction of one or more organ on admission to the study hospital with the most common being that of coagulation (57.1\% or 226/393). SOFA performed well in prediction of mortality in those patients initially admitted to the critical care unit (AUC 0.858, $95 \% \mathrm{Cl} 0.793-0.922$ ) but poor in those admitted to medical wards (AUC $0.667,95 \% \mathrm{Cl} 0.577-0.758$ ). In contrast qSOFA had poor predictive validity in both settings (AUC $0.692,95 \% \mathrm{Cl} 0.605-0.780$ and AUC 0.527, 95\%Cl 0.424-0.630, respectively). The overall case fatality rate was $28 \%$. HIV infection $(H R=3.145, p=0.001)$, neutropenia $(H R=2.442, p=0$. 002), SOFA score 1-point increment $(H R=1.19, p<0.001)$ and infection with Enterobacteriaceae $(H R=1.722, p=0.037)$ were independent risk factors for in-hospital mortality.
\end{abstract}

Conclusions: Organ dysfunction was common among Vietnamese patients with CABSI and associated with high case fatality. SOFA and qSOFA both need to be further validated in this setting.

Keywords: Bloodstream infection, Organ failure, Sequential organ failure assessment score, SOFA, qSOFA, Inflammatory markers, Procalcitonin, C-reactive protein

\section{Background}

Bloodstream infection (BSI) is a common cause of sepsis and is associated with significant morbidity and in-hospital mortality worldwide [1]. It is ranked the 11th leading cause of death among adults in USA in 2014, with an age-adjusted death rate of 10.7 per 100,000 standard population [2]. In South and Southeast Asia, the

\footnotetext{
* Correspondence: datvq@hmu.edu.vn; quocdat181@yahoo.com

1 Department of Infectious Diseases, Hanoi Medical University, no 1 Ton That

Tung street, Dong Da district, Hanoi, Vietnam

${ }^{2}$ Wellcome Trust Major Overseas Programme, Oxford University Clinical

Research Unit, Hanoi, 78 Giai Phong street, Dong Da district, Hanoi, Vietnam Full list of author information is available at the end of the article
}

incidence rate of community-acquired BSI in the period of 2004-2010 increased from 16.7 to 38.1 per 100,000 people per year and the 30 days mortality rate can reach up to $37.5 \%$ [3].

In patients with BSI, an increasing number of organs with dysfunction is correlated with increased morbidity and mortality [4]. Multiple organ dysfunction is a leading cause of morbidity and mortality in patients admitted to intensive care units (ICUs) in Europe, with an in-hospital mortality of $34.2 \%$ [5]. Sequential organ failure assessment (SOFA) score, and the related qSOFA (quickSOFA) score have been recently recommended for

(c) The Author(s). 2018 Open Access This article is distributed under the terms of the Creative Commons Attribution 4.0 International License (http://creativecommons.org/licenses/by/4.0/), which permits unrestricted use, distribution, and reproduction in any medium, provided you give appropriate credit to the original author(s) and the source, provide a link to the Creative Commons license, and indicate if changes were made. The Creative Commons Public Domain Dedication waiver (http://creativecommons.org/publicdomain/zero/1.0/) applies to the data made available in this article, unless otherwise stated. 
identifying sepsis and predicting outcome by the Third International Consensus Definitions for Sepsis and Septic Shock (Sepsis-3) [6]. qSOFA was originally designed for use outside the ICU, but it's simplicity, brevity and lack of laboratory results, make it compelling for use in emergency departments and resource-constrained setting. However the validation of qSOFA is not consistent among studies quantifying the risk of death in those presenting with suspected infection in critical care [6-9]. Development and validation of these scores were mostly carried out in high income countries, with limited data on their validity in low- and middle income countries (LMICs) [7, 8, 10]. Additionally there have been few studies looking specifically at patients with BSI, a population with an associated increase in mortality.

This study aims to describe the clinical manifestations and associated organ dysfunctions as described by Sequential [Sepsis-related] Organ Failure Assessment (SOFA) scores and its correlation with mortality in patients with community acquired bloodstream infection at the time of presenting to a large teaching hospital in Vietnam, and their associated mortality.

\section{Methods}

\section{Study design}

This was a retrospective, cohort study of patients hospitalised at the National Hospital for Tropical Diseases (NHTD) (a tertiary referral infectious disease hospital) in northern Vietnam between January 2011 and December 2013. As a referral centre, this hospital often receives patients with specific infections (eg. central nervous system infections), complicated infections and those with severe infections who have failed on treatment elsewhere. Additionally, at the time of the study, the hospital had not establish a separate emergency department and intensive care unit (ICU), therefore we refer to the critical care unit (CCU) for the unit with both ventilated and unventilated beds, available haemodynamic support and renal replacement therapy. A convenience sampling method was used to select medical notes from the list of all hospitalised patients with positive bacterial blood cultures during the study period. The inclusion criteria were having a blood culture, taken within $48 \mathrm{~h}$ of hospitalisation (to any institution) for the current admission, positive for a recognised pathogen according to the US CDC's National Healthcare Safety Network (NHSN) list [11]. Patients with infection with more than one bacterium were excluded, as were cases considered to be pseudobacteraemia [12].

\section{Data collection}

Data was extracted from patients' medical notes using a case-report form that captured patient demographics, reported history of prior medical illness, clinical manifestations, laboratory results, inflammatory markers within the first $24 \mathrm{~h}$ of admission to the study hospital and outcome at hospital discharge.

BSI with concurrent meningitis was defined in bacteremic patients who had cerebrospinal fluid examination within $24 \mathrm{~h}$ of blood drawn for microorganism isolation showing at least one of the following criteria: (1) turbid appearance; (2) leukocytosis (> 100 cells $/ \mathrm{mm} 3$ ) or (3) leukocytosis from 10 to 100 cells/ mm3) and either an elevated protein $(>100 \mathrm{mg} / \mathrm{dl})$ or decreased glucose $(<40 \mathrm{mg} / \mathrm{dl})$ [13]. BSI with concurrent pneumonia was confirmed by radiology within $24 \mathrm{~h}$ of blood drawn for microorganism isolation. Gastrointestinal tract infection and urine tract infection were defined by the $\mathrm{CDC} /$ NHSN Surveillance Definitions for Specific Types of Infections [14]. Sequential [Sepsis-related] Organ Failure Assessment (SOFA) score, and quick SOFA (qSOFA) score were calculated using the worst parameters recorded within the first $24 \mathrm{~h}$ of admission to the study hospital and missing values were considered to be normal [6]. Organ dysfunction was defined by organ-specific SOFA scores $\geq 1$. Failure of kidney function was further evaluated using the RIFLE criteria with RIFLE-F (Failure) defined as patients with a serum creatinine greater than three times the age adjusted upper limit of serum creatinine [15]. Neutropenia was defined as an absolute neutrophil count $<1500$ cells $/ \mathrm{mm}^{3}$, severe anemia as hemoglobin concentration was $<80 \mathrm{~g} / \mathrm{L}$ and thrombocytopenia as a platelet count below $100 \times 10^{3}$ cells $/ \mathrm{mm}^{3}$.

The outcome at hospital discharge was defined as death for those who died in hospital or were palliatively discharged (discharged home for palliative care with the expectation of an early death, as per common practice in Vietnam) and 'survived' in all other cases.

\section{Data analysis}

Data was analysed using IBM SPSS Statistics for Windows (IBM Corp., Armonk, NY). Depending on the distribution, continuous data were presented as mean (95\% confidence interval) or median (interquartile range) and categorical data as number (percentage). To evaluate the predictive value of SOFA, qSOFA score, white blood cell counts, C-Reactive Protein (CRP) and procalcitonin levels, a receiver operating characteristic (ROC) curve and the area under the curve (AUC) were calculated along with the sensitivity, specificity, positive and negative predictive values, positive and negative likelihood ratios associated with the cut-off value that gave the highest difference between sensitivity and (1-specificity) (Youden index). Since procalcitonin level was obtained by a semi-quantitative test that was only quantitatively measured for levels under $100 \mathrm{ng} / \mathrm{mL}$, the result of "above $100 \mathrm{ng} / \mathrm{mL}$ " was considered as $100 \mathrm{ng} / \mathrm{mL}$. The Mann Whitney U test and Kruskal Wallis test were used to analyze continuous variables 
and the Chi-square and Fisher's exact were used for bivariate analyses as appropriated. Logistic regression models were used to calculate unadjusted odds ratios (ORs) and 95\% confidence intervals (CIs) for associations between clinical, laboratory characteristics and case fatality rate. Comparison of AUC between different ROC curves was performed using a nonparametric approach [16]. Cox proportional hazards regression was used to identify variables that predicted clinical outcomes. Variables for inclusion were selected by review of the literature (age, HIV infection status, neutropenia, SOFA score and aetiology of CABSI). All tests were two-tailed and differences were considered statistically significant at $p$ values $\leq 0.05$.

\section{Results}

Among 400 patients with community acquired bloodstream infections (CABSI) there were 393 patients with infection with one bacterium included in this analysis, 7 dual infection cases were excluded (including $3 \mathrm{HIV}$ infected cases with co-infection of T. marneffei and S. aureus, Escherichia hermannii or Salmonella group $D ; 1$ case with $S$. aureus and $K$. pneumoniae, 1 case with Enterococcus faecalis and viridans streptococci, 1 case with E. coli and K. pneumoniae and 1 case with S. aureus and E. coli co-infection). Gram-negative bacteria dominated (70.7\%, 278/393), comprising Enterobacteriaceae (50.9\%, 200/393) and non-Enterobacteriaceae Gram-negative bacteria $(19.8 \%, 78 / 393)$ followed by Gram-positive bacteria $29.3 \%(115 / 393)$.

Clinical characteristics, aetiology of CABSI and organ failure The median age of patients included was 48 years (IQR 36-60), with 271 males and a male to female ratio of $2.2: 1$. There was a history of chronic disease in $27 \%$ of patients, with the highest prevalence in patients with $E n$ terobacteriaceae BSI, 34\% (38/200). Thirty-eight percent (150/393) of patients were transferred from another hospital $(<48 \mathrm{~h})$ for the current illness episode. The median time from onset of illness to hospitalisation at the study site was 5 days and $36.9 \%$ (145/393) were admitted directly to critical care.

Concurrent meningitis was confirmed in 18.3\% (72/ 393 ) and pneumonia in $24.9 \%$ (98/393) of patients, with both conditions occurring in $2.8 \%(11 / 393)$ of patients with CABSI. Gram-positive organisms were isolated from $72.2 \%$ (52/72) of those with meningitis, Enterobacteriaceae in $18.1 \%(13 / 72)$ and non-Enterobacteriaceae Gram-negative bacteria in $9.7 \%$ (7/72), see Table 1 for details. Concurrent meningitis was found in 6.5\% (13/ 200) patients with Enterobacteriaceae BSI, 9.0\% (7/71) patients with non-Enterobacteriaceae Gram-negative bacteria BSI and $45.2 \%(52 / 115)$ patients with gram positive BSI. In the 98 cases of pneumonia the causative pathogens isolated from blood were Enterobacteriaceae
(46.9\%, 46/98), non-Enterobacteriaceae Gram-negative bacteria $(25.5 \%, 25 / 98)$ and Gram-positive bacteria (27.6\%, 27/98) (see Additional file 1: Table S1).

A further $8.4 \%$ (33/393) of patients presented with or developed at least one abscess, of which 2 patients (6.1\%) had 2 abscess foci and 1 patient (3.0\%) had 3 abscess foci in different locations. The locations were $16 /$ 37 (43.2\%) liver, 8 (21\%) skin, 4 (10.8\%) muscle, 3 (8.1\%) brain, 3 (8.1\%) spleen, 2 (5.4\%) lung, 1 (2.7\%) eyelid. Endocarditis was confirmed by echocardiography in $4.1 \%$ $(16 / 393)$ patients. These were due to Staphylococcus aureus $(7 / 16,43.8 \%)$, viridans group streptococci $(4 / 16$, 28.6\%), Enterococcus species (3/16, 18.8\%), Klebsiella pneumoniae $(1 / 16,6.25 \%)$ and Pseudomonas aeruginosa $(1 / 16,6.25 \%)$. The distribution of aetiology by the foci of infection is presented in Additional file 1: Table S1.

On the day of admission to the study hospital, BSI patients had a median SOFA score of 3 (IQR 1-7) and $78.1 \%$ (307/393) of patients had dysfunction of at least one organ. The SOFA score differed significantly between patients admitted direct to CCU (median of 7 , IQR 4-12) and medical wards (median of 2, IQR 0-4) $(p<0.001)$. Enterobacteriaceae BSIs accounted for most cases with SOFA score above 12 ( $74 \%$ or $28 / 38$, vs. $48 \%$ $(172 / 355)$ in patients with SOFA score $\leq 12, p=0.003)$ or more than 3 organ dysfunctions ( $60 \%$ or $47 / 78$, vs. $49 \%$ or $153 / 315$ in patients with $\leq 3$ organ dysfunctions, $p=0.065)$. qSOFA score was $\geq 2$ in $28.6 \%(71 / 248)$ of patients that were initially admitted to medical wards. The unadjusted associations between clinical factors and case fatality are presented in Table 1.

\section{Laboratory results and inflammatory markers}

The proportions of patients with white blood cells count $<4 \times 10^{9} / \mathrm{l}, 4-12 \times 10^{9} / 1$ and $>12 \times 10^{9} / \mathrm{l}$ were $11.8 \%(46 /$ $389), 47 \%(183 / 389)$ and $41.1 \%(160 / 389)$ respectively. Neutropenia, severe anaemia and thrombocytopenia was presented in $7.2 \%(28 / 388), 8 \%(31 / 389)$ and $43.4 \%(169 /$ 389) patients with BSI on admission to the study hospital, respectively. The proportion of patients with RIFLE-F, increased lactate, procalcitonin or CRP were not significantly different when classified by bacterial aetiology (Enterobacteriaceae, non-Enterobacteriaceae and Gram-positive). Lactate levels were only available for 73 patients and 52/73 (69.9\%) patients had lactate level $\geq 2 \mathrm{mmol} / \mathrm{L}$ on admission. The median lactate level increased significantly with increasing SOFA score; from $1.23 \mathrm{mmol} / \mathrm{L}$ (IQR: $0.99-2.04 \mathrm{mmol} / \mathrm{L}$ ) in those with a SOFA score $<6$, to $7.89 \mathrm{mmol} / \mathrm{L}$ (IQR: $3.7-10.38$ ) in those with a SOFA score $>12(p<0.001$, Kruskal Wallis test). There was no significant difference between median lactate levels in those with qSOFA $<2$ and qSOFA $\geq 2$ ( $p=0.055$, Mann-Whitney U test). Laboratory factors associated with case mortality was showed in 
Table 1 Clinical characteristic on admission of patients with bloodstream infection

\begin{tabular}{|c|c|c|c|c|}
\hline Factor & Proportion & Case fatality rate & Unadjusted odds ratios $(95 \% \mathrm{Cl})$ for case fatality & $P$ values \\
\hline \multicolumn{5}{|l|}{ Age (yrs) } \\
\hline$\leq 40$ years old & 122/393 (31\%) & $27(22.1 \%)$ & 1 & \\
\hline $41-55$ years old & 152/393 (38.7\%) & $46(30.3 \%)$ & $1.527(0.881-2.646)$ & 0.131 \\
\hline$\geq 56$ years old & 119/393 (30.3\%) & $37(31.1 \%)_{-}$ & $1.588(0.891-2.828)$ & 0.117 \\
\hline Male sex (\%) & $271 / 393(69.0 \%)$ & $84(31.0 \%)$ & $1.659(1.002-2.746)$ & 0.049 \\
\hline Any previous hospitalisation (\%) & 150/393 (38.2\%) & $62(41.3 \%)$ & $2.862(1.819-4.503)$ & $<0.001$ \\
\hline Any antibiotic prior to NHTD hospitalisation (\%) & $50 / 150(33.3 \%)$ & $23(46.0 \%)$ & $1.332(0.671-2.646)$ & 0.412 \\
\hline Time from onset to current hospitalisation $<5$ days & $217 / 393(55.2 \%)$ & $57(26.3 \%)$ & $0.827(0.532-1.286)$ & 0.399 \\
\hline Direct ICU admission & 145/393 (36.9\%) & $68(46.9 \%)$ & $4.331(2.720-6.898)$ & $<0.001$ \\
\hline Any history of medical disease & 106/393 (27.0\%) & $44(41.5 \%)$ & $2.376(1.479-3.818)$ & $<0.001$ \\
\hline HIV & 19/393 (4.8\%) & $10(52.6 \%)$ & $3.044(1.202-7.710)$ & 0.019 \\
\hline Moderate or severe liver disease & $53 / 393(13.5 \%)$ & $25(47.2 \%)$ & $2.679(1.481-4.844)$ & 0.001 \\
\hline Diabetes & 25/393 (6.4\%) & 7 (28.0\%) & $1.001(0.406-2.466)$ & 0.999 \\
\hline \multicolumn{5}{|l|}{ Concurrent foci of infection } \\
\hline Radiology-confirmed pneumonia on admission & $98 / 393(24.9 \%)^{a}$ & $29(29.6 \%)$ & $1.11(0.671-1.837)$ & 0.684 \\
\hline $\begin{array}{l}\text { Lumbar puncture confirmed meningitis } \\
\text { on admission }\end{array}$ & $72 / 393(18.3 \%)^{b}$ & $19(26.4 \%)$ & $0.906(0.509-1.614)$ & 0.738 \\
\hline Heart valve vegetations during hospitalisation & 16/393 (4.1\%) & $4(25.0 \%)$ & $0.852(0.269-2.701)$ & 0.786 \\
\hline Any abscess during hospitalisation & $33 / 393(8.4 \%)^{c}$ & $6(18.2 \%)$ & $0.547(0.219-1.364)$ & 0.196 \\
\hline \multicolumn{5}{|l|}{ Organ dysfunction on admission } \\
\hline Cardiovascular & $65 / 393(16.5 \%)$ & $52(80.0 \%)$ & $18.621(9.522-36.415)$ & $<0.001$ \\
\hline Respiratory & $87 / 393(22.1 \%)$ & $53(60.9 \%)$ & $6.81(4.057-11.431)$ & $<0.001$ \\
\hline CNS & 105/393 (26.7\%) & $55(52.4 \%)$ & $4.66(2.876-7.551)$ & $<0.001$ \\
\hline Hepatic & 146/393 (37.2\%) & 57 (39.0\%) & $2.344(1.494-3.678)$ & $<0.001$ \\
\hline Renal & 153/393 (38.9\%) & $66(43.1 \%)$ & 3.379 (2.139-5.339) & $<0.001$ \\
\hline Coagulation & 226/393 (57.5\%) & $85(37.6 \%)$ & $3.424(2.070-5.663)$ & $<0.001$ \\
\hline
\end{tabular}

asolates from blood in patients with pneumonia were K. pneumoniae (22.4\%, 22/98), E. coli (16.3\%, 16/98), S. maltophilia (11.2\%, 11/98), Burkholderia pseudomallei $(8.2 \%, 8 / 98)$, S. aureus $(7.1 \%, 7 / 98)$ and S. suis $(7.1 \%, 7 / 98)$ and other pathogens $(23.5 \%, 27 / 98)$

bIsolates from blood in patients with meningitis were S. suis (40/72, 55.6\%), K. pneumoniae (8/72, 11.1\%), Stenotrophomonas maltophilia (7/72, 9.7\%), S. aureus (5/72, 6.9\%). Enterococcus species (2/72, 2.8\%), Listeria species (2/72, 2.8\%), E. coli (2/72, 2,8\%), Salmonella enterica (2/72,2.8\%) and each of S. pneumoniae, beta hemolytic Streptococcus, viridans group Streptococcus and Enterobacter species (1/72, 1.4\%)

${ }^{C}$ There were 16 cases with liver abscess with isolates from blood were K. pneumoniae (8/16 or 50\%), E. coli and Salmonella enterica (2/16 of each, or $\left.12.5 \%\right)$, Aeromonas species, Enterobacter species, S. suis and viridans group streptococci (1/16 of each, 6.3\%)

Table 2. There was no unadjusted associated between procalcitonin and CRP levels with case fatality rates.

\section{Mortality and associated factors}

The overall case-fatality of CABSI was $28 \%$ (110/393), of which $71.8 \%$ (79/110) occurred within 7 days of admission to the study hospital. Case fatality rates in patients with CABSI due to Enterobacteriaceae, non-Enterobacteriaceae Gram-negative bacteria and Gram-positive bacteria were $33.5 \%, 25.6 \%$ and $20 \%$, respectively. Among the most common isolates, the case fatality was $35.2 \%(31 / 88)$ in K. pneumoniae, 32.8\% (21/64) in Escherichia coli, 9.3\% (4/43) in Streptococcus suis, 15.4\% (6/39) in Stenotrophomonas maltophilia and $32.4 \%(11 / 34)$ in S. aureus. The case-fatality in patients directly admitted to CCU was $46.9 \%$ (68/145).
Organ dysfunction was associated with higher risk of in-hospital mortality (33.2\% patients with at least one organ dysfunction on admission to the study hospital vs $9.3 \%$ patients without, $p<0.001)$. Case fatality rate increased with increasing SOFA score (Fig. 1). The mortality in patients with 1, 2, 3 and more than 4 organs dysfunction was $17 \%$ (17/100), 19.5\% (16/82), 31.9\% (15/47) and 69.2\% (54/78), respectively. The highest case fatality rates were observed in patients with cardiovascular, respiratory and central nervous system (CNS) dysfunction, 80\% (52/65), 60.9\% (53/ 87), $52.4 \%$ (55/105), respectively. qSOFA $<2$ was associated with lower mortality compared with qSOFA $\geq 2,18.8 \%$ (26/ $138)$ vs $40.6 \%(63 / 155), p<0.001$. Among patients admitted directly to CCU, SOFA performed well at predicting in-hospital mortality (AUC 0.858, 95\%CI 0.793-0.922) 
Table 2 Laboratory characteristics on admission

\begin{tabular}{|c|c|c|c|c|}
\hline & Proportion & Case fatality & Unadjusted odds ratios $(95 \% \mathrm{Cl})$ for case fatality & $P$ values \\
\hline Neutropenia $(<1500$ cell/mm³) (\%) & $28 / 388(7.2 \%)$ & $22(78.6 \%)$ & $11.682(4.588-29.746)$ & $<0.001$ \\
\hline Hemoglobin< $<80 \mathrm{~g} / \mathrm{L}$ & $31 / 389(8.0 \%)$ & $11(35.5 \%)$ & $1.459(0.675-3.156)$ & 0.337 \\
\hline \multicolumn{5}{|l|}{ RIFLE criteria } \\
\hline No renal dysfunction & 283/386 (73.3\%) & $56(19.8 \%)$ & 1 & \\
\hline RIFLE-risk & $50 / 386(13.0 \%)$ & $16(32.0 \%)$ & $1.908(0.984-3.699)$ & 0.056 \\
\hline RIFLE-failure & $52 / 386(13.5 \%)$ & $35(67.3 \%)$ & $8.346(4.361-15.971)$ & $<0.001$ \\
\hline Hypoalbuminemia (albumin $\leq 30 \mathrm{~g} / \mathrm{L}$ ) & $72 / 245(29.4 \%)$ & $39(54.2 \%)$ & $3.263(1.839-5.789)$ & $<0.001$ \\
\hline Aspartate Aminotransferase (AST) $\geq 2$ ULN & $153 / 379(40.4 \%)$ & $65(42.5 \%)$ & $3.435(2.150-5.487)$ & $<0.001$ \\
\hline Alanine aminotransferase $(\mathrm{ALT}) \geq 2$ ULN & 109/378 (28.8\%) & $45(41.3 \%)$ & $2.449(1.520-3.947)$ & $<0.001$ \\
\hline Platelet $<100 \times 10^{3} / \mathrm{mm}^{3}$ & $169 / 389(43.4 \%)$ & $70(41.4 \%)$ & $3.282(2.068-5.208)$ & $<0.001$ \\
\hline \multicolumn{5}{|l|}{ Procalcitonin } \\
\hline $\mathrm{PCT} \leq 0.005 \mathrm{ng} / \mathrm{mL}(\%)$ & $6 / 239(2.5 \%)$ & $2(33.3 \%)$ & 1 & \\
\hline$P C T>0.005-2 \mathrm{ng} / \mathrm{mL}(\%)$ & $83 / 239(34.7 \%)$ & $11(13.3 \%)$ & $0.306(0.050-1.871)$ & 0.2 \\
\hline $\mathrm{PCT}>2-10 \mathrm{ng} / \mathrm{mL}(\%)$ & $59 / 239(24.7 \%)$ & $20(33.9 \%)$ & $1.026(0.173-6.087)$ & 0.978 \\
\hline $\mathrm{PCT}>10-100 \mathrm{ng} / \mathrm{mL}(\%)$ & $69 / 239(28.9 \%)$ & $29(42.0 \%)$ & $1.45(0.249-8.457)$ & 0.68 \\
\hline $\mathrm{PCT}>100 \mathrm{ng} / \mathrm{mL}(\%)$ & $22 / 239(9.2 \%)$ & $14(63.6 \%)$ & $3.5(0.520-23.559)$ & 0.198 \\
\hline \multicolumn{5}{|l|}{ C-reactive protein (CRP) (median, IQR) (mg/L) } \\
\hline CRP less than $5 \mathrm{mg} / \mathrm{L}(\%)$ & $14 / 341(4.1 \%)$ & $4(28.6 \%)$ & 1 & \\
\hline CRP from 5.01 to $20 \mathrm{mg} / \mathrm{L}(\%)$ & $26 / 341(7.6 \%)$ & $4(15.4 \%)$ & $0.455(0.094-2.195)$ & 0.326 \\
\hline CRP from 20.001 to $100 \mathrm{mg} / \mathrm{L}(\%)$ & $112 / 341(32.8 \%)$ & $29(25.9 \%)$ & $0.873(0.254-3.001)$ & 0.83 \\
\hline CRP more than 100 mg/L (\%) & 189/341 (55.4\%) & $56(29.6 \%)$ & $1.053(0.317-3.498)$ & 0.933 \\
\hline
\end{tabular}

ULN upper limit of normal; RIFLE Risk, Injury, Failure, Loss of kidney function, and End-stage kidney disease

while qSOFA was a poor predictor (AUC 0.692, 95\%CI $0.605-0.780)$ in this population. However, outside of CCU, regardless of eventual CCU admission, both SOFA and qSOFA had poor predictive validity (AUC 0.667, 95\%CI 0.577-0.758 and AUC 0.527, 95\%CI $0.424-0.630$, respectively).
Table 3 shows the prognostic validity of the Youden index of SOFA, qSOFA, WBC, CRP and PCT on admission to NHTD in all patients. The SOFA score was more accurate than QSOFA in predicting mortality $(\mathrm{AUC}=$ 0.795 vs $0.658, p<0.001)$; PCT (AUC $=0.703)$, and WBC $(\mathrm{AUC}=0.642)$ was more accurate than CRP $(\mathrm{AUC}=$

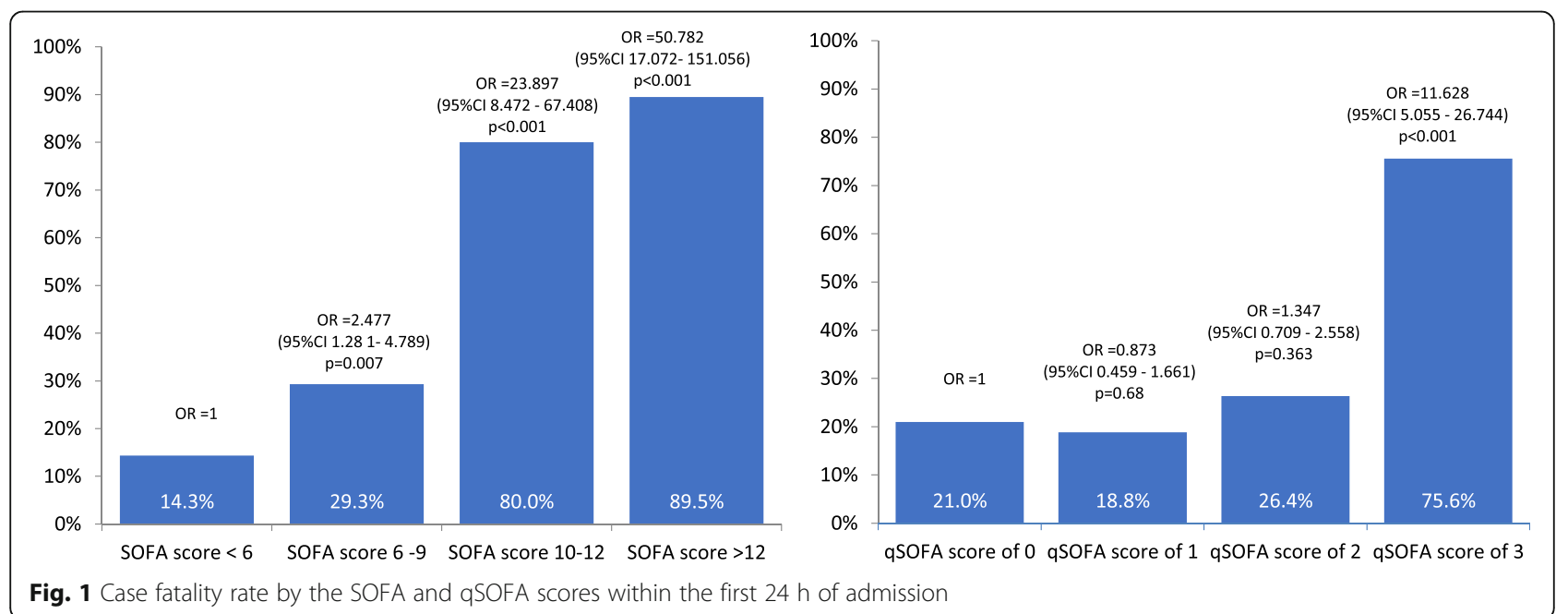


Table 3 Performance of initial SOFA score, qSOFA score, white blood cells, C-reactive protein and procalcitonin, in prediction of inhospital mortality

\begin{tabular}{|c|c|c|c|c|c|}
\hline & $\begin{array}{l}\text { SOFA } \\
(n=393)\end{array}$ & $\begin{array}{l}\text { qSOFA } \\
(n=393)\end{array}$ & $\begin{array}{l}\text { WBC } \\
(n=389)\end{array}$ & $\begin{array}{l}\text { CRP } \\
(n=341)\end{array}$ & $\begin{array}{l}\text { Procalcitonin } \\
(n=239)\end{array}$ \\
\hline $\mathrm{AUC}(95 \% \mathrm{Cl})$ & $\begin{array}{l}0.795 \\
(0.741-0.850)\end{array}$ & $\begin{array}{l}0.658 \\
(0.595-0.721)\end{array}$ & $\begin{array}{l}0.642 \\
(0.576-0.708)\end{array}$ & $\begin{array}{l}0.561 \\
(0.492-0.630)\end{array}$ & $\begin{array}{l}0.703 \\
(0.629-0.776)\end{array}$ \\
\hline Cut-off value & $\geq 9$ & $\geq 3$ & $\leq 7.39$ & $\geq 210$ & $\geq 5.49$ \\
\hline Sensitivity & $53.6 \%$ & $30.9 \%$ & $77.9 \%$ & $35.5 \%$ & $69.7 \%$ \\
\hline Specificity & $94.7 \%$ & $96.1 \%$ & $49.5 \%$ & $75.8 \%$ & $63.2 \%$ \\
\hline Positive predictive value & $79.7 \%$ & $75.6 \%$ & $79.9 \%$ & $35.5 \%$ & $46.9 \%$ \\
\hline Negative predictive value & $84.0 \%$ & $78.2 \%$ & $46.6 \%$ & $75.8 \%$ & $81.8 \%$ \\
\hline Positive likelihood ratio & 10.1194 & 7.9521 & 1.5430 & 1.4667 & 1.8945 \\
\hline Negative likelihood ratio & 0.4896 & 0.7189 & 0.4470 & 0.8511 & 0.4789 \\
\hline
\end{tabular}

SOFA Sequential Organ Failure Assessment, qSOFA quick Sequential Organ Failure Assessment, WBC white blood cell, CRP C-reactive protein

$0.561)$ in predicting mortality $(P<0.001$ and $P=0.0498$ respectively).

In unadjusted association analysis, higher mortality was associated with male sex, any previous hospitalisation, direct CCU admission, history of HIV infection, moderate severe liver diseases and. Analysis, male sex, previous hospitalisation prior to NHTD admission, any history of chronic disease, history of moderate or severe liver diseases, HIV infection, organ dysfunctions on admission, neutropenia, haemoglobin $<80$ g/L, RIFLE failure (RIFLE-F), hypoalbuminemia $(<30 \mathrm{~g} / \mathrm{L})$, elevated liver enzymes $(>2$ times the upper limit of normal), thrombocytopenia $\left(<100 \times 10^{3} /\right.$ $\mathrm{mm}^{3}$ ) and were associated with increased in-hospital mortality ( $p$ values $<0.05$ ). In Cox regression proportional hazards model, HIV infection (HR $=3.145, p=0.001)$, neutropenia $(\mathrm{HR}=2.442, p=0.002)$, SOFA score 1-point increment $(\mathrm{HR}=1.19, p<0.001)$ and infection with Enterobacteriaceae ( $\mathrm{HR}=1.722, p=0.037$ ) were significant risk factors for in-hospital mortality (Table 4).

\section{Discussion}

This retrospective study describes the clinical characteristics and outcomes in this high-risk group of patients with community acquired BSI. Multi-organ dysfunction and case-fatality rates were high in all aetiological bacterial groups. SOFA score on CCU admission had good prognostic accuracy for in-hospital mortality whilst qSOFA, WBC, CRP and PCT did not.

BSI patients admitted directly to CCU in our study had a median SOFA score of 7 (IQR 4-12), comparable with large-scale validation studies of Sepsis-3 criteria in the US (median of 6, IQR 3-9) [10] and Australia and New Zealand (median of 5, IQR 3-8) [7]. The proportion of bacteraemic patients with qSOFA of 2 or above in our study (39.4\%) was also higher than in studies of sepsis conducted in high income countries $(10-27 \%)[8,10]$. The percentage of patients with pneumonia in our CABSI cohort (24.9\%) was lower than or similar to other studies on CABSI (24-38\%) [17-19]. K. pneumoniae was the most common pathogen isolated from bacteremic patients with pneumonia in our study, reflecting its role here as an important cause of community acquired pneumonia [20]. We also confirmed the role of $S$. suis as the leading pathogen causing BSI associated with meningitis in Viet Nam [21]. Our findings further confirmed the reduction of Neisseria meningitidis in Viet Nam which was reported in $0.5 \%$ of blood isolates [22] and around $4.4 \%$ of cerebral spinal fluid (CSF) isolates before 2005 [23]. We also report the high prevalence of Enterobacteriacaea (18.1\% or 13/72) as a cause of meningitis in adult BSI patients compared to previous studies from Viet Nam (13.5\% or 30/222 of CSF isolates from 1996 and 2005) [23], Iceland (11.3\% or 12/106

Table 4 Cox proportional hazards model of factors associated with all-cause in-hospital case fatality

\begin{tabular}{lll}
\hline Variable & Hazard ratio $(95 \% \mathrm{Cl})$ & $P$-value \\
\hline Age (each increase of 1 year) & $1.006(0.994-1.019)$ & 0.321 \\
HIV infection & $3.145(1.569-6.305)$ & 0.001 \\
Absolute neutrophil count $<1500$ cells $/ \mathrm{mm}^{3}$ & $2.442(1.381-4.319)$ & 0.002 \\
SOFA score (each increase of 1 point) & $1.190(1.146-1.235)$ & $<0.001$ \\
Aetiology of CABSI (gram-positive bacterial infection as reference) & & 0.037 \\
$\quad$ Enterobacteriaceae infections & $1.722(1.034-2.869)$ & 0.178 \\
$\quad$ Non Enterobacteriaceae Gram-negative infections & $1.528(0.824-2.834)$ & \\
\hline
\end{tabular}


of positive CSF cultures during 1995-2010) [24] and Denmark (6.1\% or 88/1437 during 1991-2000) [25]. The high prevalence of meningitis associated with Enterobacteriaceae in this setting may be related to Strongyloides hyperinfection, given the evidence for high seroprevalence of Strongyloides infection in this population [26].

A review of CABSI in south and Southeast Asia from 1990 to 2010 showed the most frequent isolates in adult patients were Salmonella enterica (37.8\%), S. aureus $(12.6 \%)$ and E. coli (12\%) with an overall case fatality rate of 9\% [27]. In North America and Europe, there was a significant increase in bloodstream infection caused by Gram-negative bacteria, and case fatality rates in the period 1992-2008 were $13-20.6 \%$ in patients with CABSI [1]. The overall case fatality of $28 \%$ in our CABSI patients was lower than in a study in Thailand [3] from 2004 and 2010 (37.5\%) where the most common pathogens were E. coli (23.1\%), Burkholderia pseudomallei (19.3\%), and $S$. aureus (8.2\%) but higher than in Cambodia (22.1\%) where there was a predominance of $E$. coli (29.7\%), Salmonella spp. (14.4\%) and B. pseudomallei (12.6\%) in the period of 2007-2010) [28]. The higher case fatality in Thailand and our study may relate to the shift in the aetiology of CABSI from Salmonella to other Gram-negative bacteria observed since the last decade.

Organ dysfunction is strongly associated with in-hospital mortality. In a multicentre study of severe sepsis in Spain, case fatality in patients with more than 4 organs with dysfunction was $78.4 \%$ [29]. From a large prospective European study, case fatality in patients with more than 3 organs with dysfunction was $58 \%$ and the, highest in-hospital mortality rates were observed in patients with coagulation failure (45\%) [5]. In high income settings, among ICU patients with suspected infection, the predictive accuracy for in-hospital mortality is higher using SOFA than qSOFA (AUC $=0.74 ; 95 \% \mathrm{CI}, 0.73-0.76$; vs $\mathrm{AUC}=0.66$; $95 \% \mathrm{CI}, 0.64-0.68)$ whilst outside of ICU, the predictive validity of $\mathrm{qSOFA}$ ( $\mathrm{AUC}=0.81 ; 95 \% \mathrm{CI}$, $0.80-0.82$ ) was better than SOFA (AUC $=0.79 ; 95 \% \mathrm{CI}$, $0.78-0.80 ; P<0.001$ ) [10]. In a prospective study of patients with suspected infection admitted to an emergency department in Norway, the qSOFA had poor performance to predict 7-day and 30-day mortality with AUCs $<0.6$ in both multiple imputation and complete case analysis [30]. The usefulness of qSOFA in low- and middle income countries has not been well established. Procalcitonin levels can serve as a useful marker to rule out sepsis and discriminate contamination from true bloodstream infection $[31,32]$. Our study shows a poor prediction of initial PCT and CRP in prediction of mortality.

Our study has some major limitations. Firstly, as the study site is a referral hospital specialising in infectious diseases, the aetiologies, clinical manifestations, severity and response to the treatment may be different from those presenting to a general hospital. Secondly, SOFA and qSOFA was calculated based on the worst parameters within $24 \mathrm{~h}$ of admission to the study hospital which may not accurately present the severity of infection at arrival. Thirdly, due to the retrospective design, the data collection was incomplete and unbalanced distribution of missing data can be a bias in the prediction models The utilisation of SOFA and qSOFA needs to be validated prospectively in other setting at different time points of assessment.

\section{Conclusions}

In conclusion, community acquired BSI has a high rate of organ dysfunction and mortality in this setting. SOFA performed well at predicting those at risk of death admitted directly to CCU, whilst qSOFA performed poorly. Further prospective validation in low- and middle income settings is needed.

\section{Additional file}

Additional file 1: Table S1. The aetiology of BSI by the foci of infection (DOCX $19 \mathrm{~kb}$ ).

\begin{abstract}
Abbreviations
AUC: Area under the curve; BSI: Bloodstream infection; CABSI: Community acquired bloodstream infection; CCU: Critical care unit; Cl: Confidence interval; CNS: Central nervous system; CRP: C-reactive protein; CSF: Cerebral spinal fluid; HR: Hazard ratio; ICU: Intensive care unit; IQR: Interquartile range; LMICs: Low- and middle income countries; NHSN: National Healthcare Safety Network; NHTD: National Hospital for Tropical Diseases; OR: Odds ratio; PCT: Procalcitonin; qSOFA: Quick sequential organ failure assessment;

ROC: Receiver operating characteristic; SOFA: Sequential organ failure assessment
\end{abstract}

\section{Acknowledgments}

We gratefully acknowledge the General Planning Department in National Hospital for Tropical Diseases for providing the list of medical records. We also thank Nguyen The Hung, Nguyen Thi Hoa, Bui Linh Chi and Hoang Bao Long for their assistance with data collection.

Funding

This study was funded by the Wellcome Trust of Great Britain.

Availability of data and materials

The datasets used and/or analysed during the current study are available from the corresponding author on reasonable request.

\section{Authors' contributions}

VQD designed the study, collected \& analysed the data and wrote the first \& final draft; NTL, VNH, NDHP collected, entered data, drafted sections of the manuscript; NTL was responsible for cleaning data, analysis and drafted sections of the manuscript; NVT, NVK contributed to study design and were responsible for laboratory and clinical care, provided revisions of the manuscript edited the final draft; HRvD and $A B$ helped with interpretation of the data, revision of the manuscript and edited the final draft; $B N$ involved to design the study, interpreted the data, revised the manuscript and edited the final draft. All authors approved of the final draft.

\section{Ethics approval and consent to participate}

The study protocol was reviewed and approved by the ethics committee of the National Hospital of Tropical Diseases in Hanoi, Vietnam (Approval No: $69 /$ HDDD-NDTU). Informed consent was waived due to the retrospective nature of the study. All patient data were anonymised prior to the analysis. 


\section{Consent for publication}

Not applicable.

\section{Competing interests}

HRvD is a member of the editorial board (Associate Editor) of the BMC Infectious Diseases. The authors otherwise declare that they have no competing interests.

\section{Publisher's Note}

Springer Nature remains neutral with regard to jurisdictional claims in published maps and institutional affiliations.

\section{Author details \\ 'Department of Infectious Diseases, Hanoi Medical University, no 1 Ton That Tung street, Dong Da district, Hanoi, Vietnam. ${ }^{2}$ Wellcome Trust Major Overseas Programme, Oxford University Clinical Research Unit, Hanoi, 78 Giai Phong street, Dong Da district, Hanoi, Vietnam. ${ }^{3}$ National Hospital for Tropical Diseases, 78 Giai Phong street, Dong Da district, Hanoi, Vietnam. ${ }^{4}$ Department of Microbiology, Hanoi Medical University, no 1 Ton That Tung street, Dong Da district, Hanoi, Vietnam. ${ }^{5}$ Nuffield Department of Clinical Medicine, Centre for Tropical Medicine, University of Oxford, Oxford, UK.}

\section{Received: 26 January 2018 Accepted: 16 October 2018}

\section{Published online: 26 October 2018}

\section{References}

1. Goto M, Al-Hasan MN. Overall burden of bloodstream infection and nosocomial bloodstream infection in North America and Europe. Clin Microbiol infect off Publ Eur Soc Clin Microbiol. Infect Dis. 2013;19:501-9.

2. Kochanek KD, Murphy SL, Xu J, Deaths T-VB. Final data for 2014. Natl vital stat rep cent dis control Prev Natl cent health stat Natl vital stat. Syst. 2016; 65:1-122.

3. Kanoksil M, Jatapai A, Peacock SJ, Limmathurotsakul D. Epidemiology, Microbiology and mortality associated with community-acquired bacteremia in Northeast Thailand: a multicenter surveillance study. PLoS One. 2013;8:e54714.

4. El-Menyar A, Thani HA, Zakaria ER, Zarour A, Tuma M, AbdulRahman H, et al. Multiple organ dysfunction syndrome (MODS): is it preventable or inevitable? Int J Clin Med. 2013;03:722.

5. Sakr Y, Lobo SM, Moreno RP, Gerlach H, Ranieri VM, Michalopoulos A, et al Patterns and early evolution of organ failure in the intensive care unit and their relation to outcome. Crit Care Lond Engl. 2012;16:R222.

6. Singer M, Deutschman CS, Seymour CW, Shankar-Hari M, Annane D, Bauer $M$, et al. The third international consensus definitions for Sepsis and septic shock (Sepsis-3). JAMA. 2016;315:801.

7. Raith EP, Udy AA, Bailey M, McGloughlin S, Maclsaac C, Bellomo R, et al. Prognostic accuracy of the SOFA score, SIRS criteria, and qSOFA score for in-hospital mortality among adults with suspected infection admitted to the intensive care unit. JAMA. 2017;317:290-300.

8. Freund $Y$, Lemachatti $N$, Krastinova $E$, Van Laer M, Claessens $Y-E$, Avondo A, et al. Prognostic accuracy of Sepsis-3 criteria for in-hospital mortality among patients with suspected infection presenting to the emergency department JAMA. 2017;317:301-8.

9. Churpek MM, Snyder A, Han X, Sokol S, Pettit N, Howell MD, et al. Quick Sepsis-related organ failure assessment, systemic inflammatory response syndrome, and early warning scores for detecting clinical deterioration in infected patients outside the intensive care unit. Am J Respir Crit Care Med. 2017;195:906-11.

10. Seymour CW, Liu VX, Iwashyna TJ, Brunkhorst FM, Rea TD, Scherag A, et al. Assessment of clinical criteria for Sepsis: for the third international consensus definitions for Sepsis and septic shock (Sepsis-3). JAMA. 2016;315: 762-74

11. Centers for Disease Control and Prevention. NHSN Organism List. 2017. https://www.cdc.gov/nhsn/xls/master-organism-com-commensals-lists.xlsx. Accessed 7 Oct 2017.

12. Dat VQ, Vu HN. Nguyen the $H$, Nguyen HT, Hoang LB, vu Tien Viet $D$, et al, bacterial bloodstream infections in a tertiary infectious diseases hospital in northern Vietnam: aetiology, drug resistance, and treatment outcome. BMC Infect Dis. 2017;17:493.

13. World Health Organization. Invasive Bacterial Vaccine Preventable Diseases (IB-VPD) Surveillance Network Case definitions. 2012. http://www.who.int/
immunization/monitoring_surveillance/resources/IB-VPD_Case_Defs.pdf Accessed 7 Oct 2017.

14. Centers for Disease Control and Prevention. CDC/NHSN Surveillance Definitions for Specific Types of Infections. 2018. https://www.cdc.gov/nhsn/ pdfs/pscmanual/17pscnosinfdef_current.pdf. Accessed 29 Aug 2018.

15. Uchino S, Bellomo R, Goldsmith D, Bates S, Ronco C. An assessment of the RIFLE criteria for acute renal failure in hospitalized patients. Crit Care Med. 2006:34:1913-7.

16. DeLong ER, DeLong DM, Clarke-Pearson DL. Comparing the areas under two or more correlated receiver operating characteristic curves: a nonparametric approach. Biometrics. 1988:44:837-45.

17. Zahar J-R, Timsit J-F, Garrouste-Orgeas M, Français A, Vesin A, Vesim A, et al. Outcomes in severe sepsis and patients with septic shock: pathogen species and infection sites are not associated with mortality. Crit Care Med. 2011:39:1886-95.

18. Park HK, Kim WY, Kim MC, Jung W, Ko BS. Quick sequential organ failure assessment compared to systemic inflammatory response syndrome for predicting sepsis in emergency department. J Crit Care. 2017;42:12-7.

19. Artero A, Zaragoza R, Camarena JJ, Sancho S, González R, Nogueira JM. Prognostic factors of mortality in patients with community-acquired bloodstream infection with severe sepsis and septic shock. J Crit Care. 2010; 25:276-81.

20. Peto L, Nadjm B, Horby P, Ngan TTD, van Doorn R, Kinh NV, et al. The bacterial aetiology of adult community-acquired pneumonia in Asia: a systematic review. Trans R Soc Trop Med Hyg. 2014;108:326-37.

21. Huong V, Ha N, Huy N, Peter H, Nghia H, Thiem V, et al. Epidemiology, clinical manifestations, and outcomes of Streptococcus suis infection in humans. Emerg Infect Dis. 2014;20:1105-14.

22. Hoa NT, Diep TS, Wain J, Parry CM, Hien TT, Smith MD, et al. Communityacquired septicaemia in southern Viet Nam: the importance of multidrugresistant Salmonella typhi. Trans R Soc Trop Med Hyg. 1998;92:503-8.

23. Mai NTH, Chau TTH, Thwaites G, Chuong LV, Sinh DX, Nghia HDT, et al. Dexamethasone in Vietnamese adolescents and adults with bacterial meningitis. N Engl J Med. 2007;357:2431-40.

24. Thornórðardóttir A, Erlendsdóttir H, Sigurðardóttir B, Harðardóttir H, Reynisson IK, Gottfreðsson M, et al. Bacterial meningitis in adults in Iceland, 1995-2010. Scand J Infect Dis. 2014;46:354-60.

25. Meyer CN, Samuelsson IS, Galle M, Bangsborg JM. Adult bacterial meningitis: aetiology, penicillin susceptibility, risk factors, prognostic factors and guidelines for empirical antibiotic treatment. Clin Microbiol Infect. 2004;10: 709-17.

26. Diep NTN, Thai PQ, Trang NNM, Jager J, Fox A, Horby P, et al. Strongyloides stercoralis seroprevalence in Vietnam. Epidemiol Infect. 2017;145(15):3214-8

27. Deen J, von Seidlein L, Andersen F, Elle N, White NJ, Lubell Y. Communityacquired bacterial bloodstream infections in developing countries in south and Southeast Asia: a systematic review. Lancet Infect Dis. 2012;12:480-7.

28. Vlieghe ER, Phe T, Smet BD, Veng HC, Kham C, Lim K, et al. Bloodstream infection among adults in Phnom Penh, Cambodia: key pathogens and resistance patterns. PLoS One. 2013;8:e59775.

29. Blanco J, Muriel-Bombín A, Sagredo V, Taboada F, Gandía F, Tamayo L, et al. Incidence, organ dysfunction and mortality in severe sepsis: a Spanish multicentre study. Crit Care. 2008:12:R158.

30. Askim $\AA$, Moser F, Gustad LT, Stene H, Gundersen M, Åsvold BO, et al. Poor performance of quick-SOFA (qSOFA) score in predicting severe sepsis and mortality - a prospective study of patients admitted with infection to the emergency department. Scand J Trauma Resusc Emerg Med. 2017;25:56.

31. Riedel S, Melendez JH, An AT, Rosenbaum JE, Zenilman JM. Procalcitonin as a marker for the detection of bacteremia and Sepsis in the emergency department. Am J Clin Pathol. 2011:135:182-9.

32. Schuetz P, Mueller B, Trampuz A. Serum Procalcitonin for discrimination of blood contamination from bloodstream infection due to coagulasenegative staphylococci. Infection. 2007;35:352. 